INTERNATIONAL JOURNAL OF MULTidisciplinARy RESEARCH AND ANALYSis

ISSN(print): 2643-9840, ISSN(online): 2643-9875

Volume 04 Issue 07 July 2021

DOI: 10.47191/ijmra/v4-i7-08, Impact Factor: 6.072

Page No.- $918-923$

\title{
Female Students' Awareness in Sexual Harassment Prevention
}

\author{
Chu Thi Huyen Yen ${ }^{1}$, Vu Thi Minh Ngoc ${ }^{2}$, Nguyen Thanh Huyen ${ }^{3}$ \\ ${ }^{1,3}$ Faculty of Social work, University of Labor and Social Affairs, Vietnam \\ ${ }^{2}$ National Academy of Public Administration, Vietnam
}

\begin{abstract}
The main objective of this study was to identify, evaluate, and to measure the attributes of female students' awareness in sexual harassment prevention in Hanoi, Vietnam. The study was based on a field survey using a semi-structured questionnaire on a sample of 150 female students. But, only 125 filled questionnaires were satisfactory and therefore included in the analysis. By using seceral statistical analytical tools, i.e. descriptive statistics, Cronbach's Alpha analysis, and ANOVA, the study has identified and measured three (3) attributes of female students' awareness in sexual harassment prevention in Hanoi, Vietnam that have great effects on female students. There is not, statistically, significant difference in the level of female students' awareness in sexual harassment prevention in Hanoi from these different universities. Based on the findings, some recommendations are given for the universities and female students to improve the awareness of sexual harassment prevention.
\end{abstract}

KEYWORDS: sexual harassment prevention, female students, social work, psychological

\section{INTRODUCTION}

According to the Vietnamese culture, sex is a delicate and sensitive issue, so teaching basic skills or knowledge about reproductive health and sex in families and schools is still not paid enough attention (Dung, 2019).

According to the survey results of Action Aid in 2016, $91 \%$ of women in the age group of 18 to $23 ; 60 \%$ of students; $59 \%$ of civil servants, $57 \%$ of domestic workers; $54 \%$ of office workers have experienced sexual harassment. Another survey conducted by Action Aid in Vietnam and the Center for Gender, Family and Environment in Development on different target groups showed that up to $87 \%$ of women and girls surveyed confirmed have been sexually harassed in public, $53.7 \%$ of office workers and $59.5 \%$ of civil servants have been sexually harassed two to five times; $89 \%$ of men and eyewitnesses saw these acts. In addition, $40 \%$ of survey respondents have witnessed acts of harassing underage girls, $47 \%$ of whom witnessed this behavior repeated many times (Ngan, 2020).

Female students are at high risk of being sexually harassed because their own physical, psycho-social characteristics make it more difficult to defend against this behavior. Female students who have just entered university are under the age that has many major changes in psycho-physiology and social roles. They have interests in issues of gender, friendship, love and sexuality. Students in general and female students in particular, are mostly young people living far away from their families. They live in unsafe hostel, work part-time and often take public transport. Many people with bad intention can take advantage of these characteristics o commit sexual harassment. In addition, some students from other provinces having little knowledge about the new living environment in the city are easy to become the target of sexual harassment (United Nation Women, 2016).

There are many causes of sexual harassment such as: Public have poor and inadequate awareness of sexual harassment; women often hide things and are afraid to publicize the matter when they are harassed, they do not have the courage to protest or denounce the harassers. Therefore, awareness in preventing sexual harassment of female students is critical and meaningful, helping female students avoid sexual harassment.

In this article, we focus on assessing and measuring female students' awareness in sexual harassment prevention, thereby proposing some recommendations for universities, colleges and female students in the university with regard to sexual harassment prevention.

\section{LITERATURE REVIEW}

There are typical studies related to the research topic as follows: 


\section{Female Students' Awareness in Sexual Harassment Prevention}

Hejase (2015) explored sexual harassment in the workplace within selected Lebanese organizations. A questionnaire has been developed and circulated to that purpose. The organizations contacted comprised of one hotel, several restaurants and night clubs, and a university. The result showed that, sexual harassment is considered to be a hot zone where the harassed still consider it a taboo. This is due to social environment, culture, norms, and values.

More than $50 \%$ of female students and about $49 \%$ of male students interviewed described sexual harassment as the main cause of their dissatisfaction with the country's university system. Sexual harassment is on the rise and has even become the norm as sex-for-grades is quite common all over the world - in some universities in Uganda (Dien San, 2018).

Dung (2019) analyzes the concept and forms of sexual harassment to help readers identify sexual harassment, analyze sexual harassment behaviors that often occur in the higher education environment. At the same time, the author analyzes and evaluates the legal provisions on handling acts of sexual harassment; thereby proposing solutions to prevent sexual harassment in schools including (i) on the school and social organizations' side; (ii) on the students' side.

Van and Chi (2019) choose a research sample of students from three universities in Hanoi, where have 14 bus routes that are mainly taken by students. This research analyzes views on sexual harassment, understanding of the causes of sexual harassment and behavioral perceptions of responding to sexual harassment based on 3 models explaining sexual harassment behavior: (i) natural biological model; (ii) socio-cultural model; and (iii) combined model. Research results show that female students' knowledge about sexual harassment tends to be better than male students. Students' attitude towards sexual harassment is at a high level of negative emotions, in which female students have higher emotional scores than male students. Male and female students both have the right thoughts and attitudes towards sexual harassment, however, men choose to remain silent or ignore sexual harassment more. The transition to positive behavior depends on many factors such as environment and circumstances, gender awareness, communication and social interactions.

There are no complete and up-to-date statistics on workplace harassment in Vietnam. But according to an online survey by the International Labor Organization published in 2018, up to $17 \%$ of respondents said that they or someone they know had "received a sexual request from a superior in exchange for benefits in the workplace". Sexual harassment in the media is a global problem. A survey in 2013 and 2014 found that 48\% of female journalists had experienced some form of sexual harassment at work, and $83 \%$ admitted that they did not report this behavior. According to the study "Women and journalism in Vietnam" conducted by the Swedish Press Training Institute in 2018, sexual harassment towards journalists is at a high level, over $27 \%$ of female reporters surveyed reported having been sexually harassed (Ngan, 2020).

Tam (2020) conducts the research on sexual harassment based on the results of previous studies, the concept of sexual harassment, the concept of identified prevention and concludes that sexual harassment prevention includes 3 attributes (indicators or scales): (i) prevent sexual harassment before it occurs; (ii) prevent the repetition of sexual harassment; (iii) prevent or limit the effects or consequences of sexual harassment by referring and providing short-term and long-term care and support services.

Raj et al. (2020) undertook a longitudinal analysis to predict effects of sexual harassment reported in 1995 on career outcomes measured in 2012-13, among a sample of women in academic medicine $(N=1273)$ recruited from 24 U.S. medical schools. Measures included survey data from 1995 on sexual harassment (predictor), and 2012-2013 data on retention in academic medicine, rank, leadership positions, and refereed publications (outcomes), captured from surveys and public records. They used multivariable models to test effects of sexual harassment on study outcomes, adjusting for socio-demographics, employmentrelated variables, and gender discrimination. The result showed that, in 1995, 54\% of women reported any workplace sexual harassment, and $32 \%$ of women reported severe harassment (e.g., threats or coercive sexual advances) in the workplace. Multivariable regression models showed no significant effects of sexual harassment. However, severe sexual harassment was

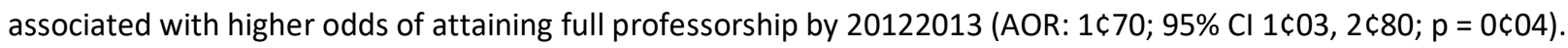

Based on the above studies, and the opinions of the interviewed experts, we build the cognitive attributes (scales) of female students in preventing sexual harassment in Table 1 as follows.

Table 1: Attributes of the female students' awareness in sexual harassment prevention

\begin{tabular}{|c|c|c|}
\hline Code & Scale & Sources \\
\hline \multicolumn{3}{|c|}{ The female students' awareness in sexual harassment prevention } \\
\hline SHP1 & Prevent sexual harassment before it occurs (prevention of "New Cases") & $\begin{array}{l}\text { Tam (2020), experts' } \\
\text { opinion }\end{array}$ \\
\hline SHP2 & $\begin{array}{l}\text { Prevent repetition of sexual harassment (make sure that the victim does not } \\
\text { continue to be sexually harassed and the perpetrator of sexual harassment } \\
\text { stops his harassment) }\end{array}$ & $\begin{array}{l}\text { Tam (2020), experts' } \\
\text { opinion }\end{array}$ \\
\hline
\end{tabular}




\begin{tabular}{|l|l|l|l|}
\hline SHP3 & $\begin{array}{l}\text { Prevent or limit the effects or consequences of sexual harassment by } \\
\text { referring and providing short-term and long-term care and support services }\end{array}$ & $\begin{array}{l}\text { Taminion } \\
\text { opinion }\end{array}$ \\
\hline
\end{tabular}

\section{METHODOLOGY}

\subsection{Context and research sample}

When attending university, students can study and live in a relatively open and dynamic environment, most of which are separated from the protection of their families. But that kind of environment poses a potential risk of sexual harassment if students do not have enough knowledge or are not equipped with skills to deal with this problem (Dung, 2019).

In the university, the educational environment, no matter how ideal it is, cannot completely eliminate the risk of sexual harassment. According to a report of the Department of Labors, War Invalids and Social Affairs (2015), sexual harassment is not only from the lecturers but also from the students; and the victim in this case may be both the students and lecturers. Recent studies show that not only women but also men can become victims of sexual harassment, but the majority of victims of sexual harassment in Vietnam are women. Sexual harassment can occur inside and outside of universities, but is usually in public places such as: Streets, parks, restrooms or public transport (Dung, 2019).

A study by CARE said that sexual harassment costs Cambodia's garment industry nearly $\$ 89$ million a year, equivalent to 0.5 percent of GDP; $13.5 \%$ of female workers in this country report that their productivity is severely reduced when they are sexually harassed. In most of the harassment case in Vietnam, that are the victim who are not protected have to resign but not the troublemaker. Harassment increases turnover rate, affects recruitment and training process, increases costs for businesses, reduces cohesion and safety in the working environment, reduces organizational effectiveness (Ngan, 2020). In addition, sexual harassment can leave the victim with consequences such as anxiety, anorexia, insomnia, depression, procrastination to go to school or work, embarrassment, society's vice, obsessive-compulsive disorder, etc.

In order to accomplish the research objective, we have sent the survey questionnaire to female students who are studing in the universities in Hanoi, including University of Labor and Social Affairs (ULSA), National Academy of Public Administration (NAPA) and Hanoi Law University (HLU). We sent all 150 questionnaires to these female students within 2 months and collected 135 votes, after cleaning the remaining 125 valid surveys to be analyzed.

\subsection{Methods of analysis}

This research used a qualitative research methodology based on some in-depth interviews with three (3) lecturers with extensive experiences in social work in Vietnam of Vietnam academy of Social sciences and University of Labor and Social Affairs.

To analyze the research data, we used SPSS22 analysis software.

We first conducted descriptive statistics.

Next, we conducted a reliability test of the scale using Cronbach's Alpha coefficient and total correlation. The Cronbach's Alpha coefficient has a variable value in the segment $[0,1]$. In theory, the higher the coefficient, the better (the more reliable the scale). Cronbach's Alpha coefficient value levels have the following meanings, From 0.8 to close to 1 : very good measurement. From 0.7 to nearly 0.8: good measurement scale. From 0.6 and above: eligible measurement scale (Henseler et al., 2015).

If a variable has a correlation coefficient of Corrected Item - Total Correlation $\geq 0.3$, that variable is satisfactory (Hair et al., 2014). Finally, we evaluated the difference by Anova with SPSS 22 software.

\section{RESEARCH RESULTS}

\subsection{Descriptive Statistics}

Table 2: Respondents by the year that students studying, and university

\begin{tabular}{|c|c|c|c|}
\hline & Frequency & Percent & Cumulative Percent \\
\hline \multicolumn{4}{|c|}{ The year that students studying } \\
\hline Freshman & 37 & 29.6 & 29.6 \\
\hline Second-year student & 35 & 28.0 & 57.6 \\
\hline Third-year student & 29 & 23.2 & 80.8 \\
\hline Final-year student & 24 & 19.2 & 100.0 \\
\hline \multicolumn{4}{|l|}{ University } \\
\hline HLU & 45 & 36.0 & 36.0 \\
\hline NAPA & 39 & 31.2 & 67.2 \\
\hline ULSA & 41 & 32.8 & 100.0 \\
\hline Total & 125 & 100.0 & \\
\hline
\end{tabular}




\section{Female Students' Awareness in Sexual Harassment Prevention}

Information of data collected is shown in Table 2. It shows that among the 125 respondents, about 29.6\% were freshmans; about 28.0\% were Second-year students; about 23.2\% were Third-year students; while the remaining 24 (19.2\%) were Final-year students. Of these, 45 of them (or 36.0\%) were from HLU, 39 of them (or 31.2\%) were from NAPA, 41 of them (or $31.2 \%$ ) were from ULSA.

Table 3. Descriptive analysis of attributes of the female students' awareness in sexual harassment prevention

\begin{tabular}{|l|l|l|l|l|l|}
\hline & N & Minimum & Maximum & Mean & Std. Deviation \\
\hline SHP1 & 125 & 2.0 & 5.0 & 3.51 & .703 \\
\hline SHP2 & 125 & 2,0 & 5.0 & 3.41 & .597 \\
\hline SHP3 & 125 & 1,0 & 5.0 & 3.44 & .712 \\
\hline $\begin{array}{l}\text { Valid } \\
\text { (listwise) }\end{array}$ & $\mathbf{1 2 5}$ & & & $\mathbf{3 . 4 5}$ & \\
\hline
\end{tabular}

Table 3 indicates that the respondents agree with the dependent variables of 'the female students' awareness in sexual harassment prevention" where three (3) attributes were quite high with an average of 3.45 compared with the highest of the Likert 5-point scale. All 3 attributes were rated at an average of 3.41 or higher.

\subsection{Cronbach's Alpha}

The female students' awareness in sexual harassment prevention has been measured by the Cronbach's Alpha. Results of testing Cronbach's alpha of attributes are presented in Table 4 below. The results also show that attributes of the dependent variables have Cronbach's Alpha coefficients that are greater than 0.6; and the correlation coefficients of all attributes are greater than 0.3. So, all the attributes of the dependent variables are statistically significant (Hair et al., 2006; Hair et al., 2014, Trong \& Ngoc, 2008).

Table 4. Results of Cronbach's Alpha Testing of Attributes

\begin{tabular}{|c|c|c|c|c|c|}
\hline Cronbach's Alpha & $\mathrm{N}$ of Items & & & & \\
\hline \multirow[t]{2}{*}{.781} & 3 & & & & \\
\hline & $\begin{array}{l}\text { Scale Mean if } \\
\text { Item Deleted }\end{array}$ & $\begin{array}{l}\text { Scale Variance if Item } \\
\text { Deleted }\end{array}$ & $\begin{array}{l}\text { Corrected Item-Total } \\
\text { Correlation }\end{array}$ & $\begin{array}{l}\text { Cronbach's } \\
\text { Deleted }\end{array}$ & Alpha if Item \\
\hline SHP1 & 6.85 & 1.356 & .599 & .727 & \\
\hline SHP2 & 6.95 & 1.594 & .582 & .745 & \\
\hline
\end{tabular}

\subsection{ANOVA}

ANOVA test was needed to make a comparison of the results of the evaluation of the female students' awareness in sexual harassment prevention between the three universities including HLU, NAPA, and ULSA. Table 5 shows that the Sig Levene Statistic of 0.722 is more than 0.05 , which means that the hypothesis of homogeneity variance among the variable value groups has not been violated. Table 6 shows that, Sig. $=0.823$ is more than 0.05 , which indicates that there is no, statistically, a significant difference in the level of the female students' awareness in sexual harassment prevention between the mentioned universities descriptions (Hair et al., 2014; Hoang \& Chu, 2008).

Table 5: Test of Homogeneity of Variances

SHP

\begin{tabular}{|l|l|l|l|}
\hline Levene Statistic & df1 & df2 & Sig. \\
\hline .326 & 2 & 122 & .722 \\
\hline
\end{tabular}

Table 6: ANOVA

SHP

\begin{tabular}{|l|l|l|l|l|l|}
\hline & Sum of Squares & Df & Mean Square & F & Sig. \\
\hline Between Groups & .124 & 2 & .062 & .195 & .823 \\
\hline Within Groups & 38.853 & 122 & .318 & & \\
\hline Total & 38.978 & 124 & & & \\
\hline
\end{tabular}




\section{Female Students' Awareness in Sexual Harassment Prevention}

\section{DISCUSSION AND IMPLICATIONS}

According Hejase (2015), Preventing sexual harassment from occurring is much less disruptive, much less expensive, and much less time consuming as compared to the time spent by supervisors investigating and litigating case-by-case incidents, doing their best to prevent sexual harassment from occurring. Therefore, prevention is the best tool for the elimination of sexual harassment. That's why the supervisor or the manager needs to have some basic education in a number of employee-relations issues, including sexual harassment. As with supervisors and managers, all others should also receive information about sexual harassment. For employees, as a whole, the emphasis should be on expectations for interpersonal behavior rather than on legal and management issues.

To universities and colleges: Prepare subjects or short courses or seminars on sexual harassment to help female students better understand sexual harassment and measures to prevent sexual harassment. Besides, universities and colleges need to install cameras in many different positions in the school; set regulations as well as severe penalties for harassment, such as reprimand in front of class and university, deduction of points for conduct; strengthen security forces at schools; closely cooperate with the local police agency to strictly handle the crime of harassment.

To female students: Students themselves must express a fierce attitude to protect themselves. Sexual harassers usually don't back down unless female students strongly express their viewpoints. Therefore, in all cases, female students should show a decisive and strong attitude when there are signs of sexual harassment. If the victim ignores the sexual harassment, it often continues and gets even worse. Remove the psychological barrier of the person being harassed. In fact, many people who experience sexual harassment are afraid of speaking the truth out because of fear or shame, so it takes courage for victims to come out or report sexual harassment. However, whether the psychological pressure of the person being harassed can be relieved or not depends much on their learning and living environment. It is necessary to create a safe, equal and fair environment so that victims may feel assured to speak up when being harassed. If you are the person experiencing sexual harassment, immediately notify the school, the competent state agencies or social organizations, even teachers, friends, family to receive guidance and support (Dung, 2019).

When being sexually harassed, female students need to keep records of evidence, information including: date, time and place when being harassed, words and behavior of the harasser, especially offensive photos, videos, phone messages or online messages. These evidences will be used to prove violations, confront the violators in case of needing to seek legal intervention (Dung, 2019).

Female students should not wear revealing clothes when going to school and public places, or going alone in deserted places.

In addition, the law of Vietnam needs to have more specific and stricter regulations and sanctions to protect those who are harassed; while protecting morality and civilized lifestyle for the whole society.

\section{REFERENCES}

1) Dien San (2018). Sexual harassment scandal in universities in Ugandan. Retrieved March 29, 2018, from: http://antg.cand.com.vn/Ho-so-Interpol/Be-boi-quay-roi-tinh-duc-trong-truong-dai-hoc-o-Uganda-484357/

2) Dung, N. T. (2019). Sexual harassment and sexual harassment prevention in the university. Transport and Communication Technology Science Journal", 33, 99-104. [Vietnamese]

3) Hair, J.F., Anderson, R.E., Tatham, R.L., \& Black, W.C. (2006). Multivariate Data Analysis. Prentice-Hall International.

4) Hair, J. F., Henseler, J., Dijkstra, T., Sarstedt, M., Ringle, C., Diamantopoulos, A., Straub, D., Ketchen, D., GTM, H., \& Calantone, R. (2014). Common beliefs and reality about partial least squares: comments on Rönkkö and Evermann. Organizational Research Methods, 17(2), 182-209.

5) Hejase, H. J. (2015). Sexual Harassment in the Workplace: An Exploratory Study from Lebanon. Journal of Management Research, 7(1), 107-121. DOI: 10.5296/jmr.v7i1.6965

6) Henseler, J., Ringle, C.M. and Sarstedt, M. (2015). A new criterion for assessing discriminant validity in variance-based structural equation modeling. Journal of the Academy of Marketing Science, 43(1), 115-135.

7) Ministry of labour, war invalids and social affairs (2015). The research report on sexual harassment in the workplace in Vietnam, in 2015.

8) Ngan, N. T. (2020). Sexual harassment. Retrieved February 29, 2020; From https://vnexpress.net/quay-roi-tinh-duc4062033.html

9) Raj, A., Freund, K. M., McDonald, J. M., \& Carr, P. L. (2020). Effects of sexual harassment on advancement of women in academic medicine: A multi-institutional longitudinal study. EClinicalMedicine, 20, 1-8.

10) Tam, L. T. (2020). Social work with group for female students in sexual harassment prevention. Doctoral thesis, Vietnam 


\section{Female Students' Awareness in Sexual Harassment Prevention}

academy of social sciences. [Vietnamese]

11) Trong, H., \& Ngoc, C. N. M. (2008). Analysis of research data with SPSS. Hong Duc Publishing House. [Vietnamese]

12) United Nation Women. (2016). Sexual harassment and forms of sexual violence against women in public places in Ho Chi Minh City. Documents of the Consultation Workshop "Results of the input survey on building a safe city for women and girls in Ho Chi Minh City. [Vietnamese]

13) Van, P. T., \& Chi, N. P. (2019). Students' perceptions and attitudes about sexual harassment behavior. Journal of research family and gender, 3, 76-87.[Vietnamese] 